\title{
Digital Economy and Law: Russian Experience
}

\author{
Juliya Kharitonova ${ }^{1,}{ }^{*}$ Larissa Sannikova ${ }^{2}$ \\ ${ }^{1}$ Business law Department of the Faculty of Law, Lomonosov Moscow State University, Moscow 19991, Russian Feder- \\ ation \\ ${ }^{2}$ Institute of State and Law of the Russian Academy of Sciences, Russian Academy of Sciences, Moscow 119019, Russian \\ Federation \\ "Corresponding author. Email: sovet2009@ rambler.ru
}

\begin{abstract}
The article deals with the problems of legislation establishment that ensure the formation and development of Russia's digital economy. Also, the concept of the "digital economy" is investigated, and a scientifically-based approach to its definition is formed. It is proposed to consider only those economic relations, which object is the new economic benefits created and functioning with the use of digital technologies as the core and the essence of the digital economy. The authors distinguish digitalization processes, which means the introduction of digital technologies, and the methods of automation and electronic document management. The article explores international leading experience in the legal regulation of new economic phenomena from the application of digital technologies. At the same time, the possible risks are also revealed, particularly technical errors and vulnerabilities in blockchain platforms that hackers can exploit. The process of economy digitalization has led to the formation of new property circulation objects, which have acquired a common name of digital assets. The article analyzes the "digital rights" category, which intermediates new objects of property circulation having digital nature. It reveals the legal digital rights definition's main drawbacks, which cause legal uncertainty for crypto investors. The authors conclude that the new Russian legislation on digital rights does not contribute to the harmonization of law in the digital economy, deprives Russia of the leading position in this sphere, and may negatively affect the investment prospects of the Russian digital assets market.
\end{abstract}

Keywords: Digital assets, Digital Economy, crypto assets, cryptocurrency, Distributed Ledger Technology.

\section{INTRODUCTION}

The digitalization of the economy has caused the occurrence of new objects inside the property circulation. They have acquired a common name of digital assets. To ensure the stability of their property turnover, to establish a legal regime for respective objects either by adapting the current civil legislation or by enacting new regulations. But to resolve the issue of establishing the legal regime for digital objects, it is necessary, primarily, to determine their legal nature, separating them from the already known legal phenomena in digital form, which are legally regulated properly.

There is no unified approach to implementing digital assets in modern literature. As the essential features of digital assets, their "binary" form and real or potential value, are rightly specified [1]. These features are reflected in the name of the new property objects.

However, these features are definitely not enough to uniquely qualify objects that exist in binary form as digital assets. In the literature, digital assets include not only tokens and cryptocurrencies, big data, domain names and accounts, virtual gaming property, but also digital content, i.e., information stored on web resources (texts, video and audio files, graphics, animation, etc.), etc., but in our opinion, it is not always reasonable.
The consideration of any digital asset as a digital asset is mainly due to the legal definition of digital assets in the Revised uniform fiduciary access to digital assets act -RUFADAA. According to provision (h) Section 870 of this act, "Digital asset" means an electronic record which a person has in a right or interest. The concept of "digital asset" does not include the underlying asset or liability unless this asset or liability is an electronic record. In this regard, "record" refers to information that is recorded on a physical medium or that is stored on an electronic or other medium and can be revealed in an accepted form ((r) Section 870).

Accordingly, digital assets are defined as "anything that can be stored and transmitted electronically (using a computer) that can be owned and therefore have the appropriate ownership and use rights" [2].

Russian leading legal experts also adhere to a broad approach to the concept of digital assets. So, Laptev [3] distinguishes:

- $\quad$ Cryptocurrencies (bitcoin, ethereum, etc.);

- Shares, bonds, shares in the authorized capital of corporations;

- Tokens (financial assets issued by a legal entity or individual entrepreneur to attract investment);

- Intellectual property (for example, musical works, works of art, books);

- Photos;

- Electronic insurance policies; 
- Smart - contract (here smart contract is considered not as a transaction, but as an independent object of law that has value);

- Personal data;

- Loyalty points etc.”.

It seems that the range of phenomena related to digital assets depends mostly on the purpose of classification. For the protection of the right to digital assets by restricting access to them, it is reasonable to define this concept as widely as possible, thereby ensuring most security. However, legal regulation of such digital assets as tokens and cryptocurrencies requires special provisions that consider the specifics of financial relations.

For other purposes, researchers can identify different types of digital assets. So, Ruan [4] outlines the following as the types of digital assets: networked system assets, software assets; hardware assets; service assets; robotic assets; data assets, metadata assets, digitally-enabled devices.

It should be noted that when ordinary objects of civil rights get a new form such as digital (electronic), there are specific problems associated with their legal regulation. From this point of view, their recognition as digital assets can be entirely substantiated. But then the concept of digital assets in a broad and restricted sense shall be distinguished.

In a broad sense, any objects of property turnover that exist in digital (electronic) form can be referred to as digital assets. In a restricted sense, digital assets should be understood as new economic objects established using digital technologies.

Outlining of digital assets category in a restricted sense is necessary, first of all, to distinguish new objects of property circulation that require the establishment of an appropriate legal regime from those objects of civil rights, which do not require a new legal regime despite although undergone modification as a result of digitalization.

\section{THE CONCEPT OF CRYPTO ASSETS}

The occurrence of the first cryptocurrency Bitcoin was a breakthrough in the financial market. In a wellknown letter signed under the pseudonym of Satoshi Nakamoto, a system of electronic transactions was proposed, based not on trust to the intermediaries as financial institutions, but on cryptography. Bitcoin quickly gained popularity in the financial market due to its advantages over traditional payment units. As the main advantage of the absence of intermediaries, which in turn reduces the cost of transactions, increases their speed, provides anonymity, and lack of control is usually noted.
The source code of Bitcoin is published in the public domain, so anyone who has the necessary knowledge and skills can create the cryptocurrency based on this code. As a result, in addition to Bitcoin, many other cryptocurrencies appeared, which are called altcoins. The total number of cryptocurrencies in the world is about two thousand.

Bitcoin and other cryptocurrencies are the results generated by the software based on blockchain technology. Their use as the means of payment caused their value in the financial market, i.e. they were considered as an asset. So, Bitcoin is not only the first and most popular cryptocurrency but also the most valuable. With the growing popularity of Bitcoin, its price also grew, which led to the use of this cryptocurrency as a commodity exchange. On the example of Bitcoin, it became clear that the result generated by the software based on the blockchain can perform other functions, and not only be the instrument of payment.

Further development of blockchain technology has led to the emergence of a more general category, such as tokens. From the economic point of view, a token is a unit of accounting used to represent the digital balance in some assets. Accordingly, possessing a token means for its owner to own a specific value in digital form.

The legal nature of the token in the literature is revealed through the description of the token functions within the digital economy. Initially, the token was considered only as an ICO tool. However, it later became clear that tokens can also serve as a means of payment; thus, the boundary between the concepts of "token" and "cryptocurrency" turned out to be blurred.

As a result, the classification of tokens proposed by the Swiss Financial Market Supervisory Authority (starting now - FINMA) [5] in the Guidelines for inquiries regarding the regulatory framework for initial coin offers (ICOs), published in 2018, has been recognized in the world. According to this classification, the following types of tokens are distinguished depending on their functions: Payment tokens perform the functions of a means of payment and represent cryptocurrencies; Utility tokens are used to pay for services or values provided by online platforms; Asset tokens from their economic function are considered as equivalent to stocks, bonds, or their derivatives. They allow trading physical assets on the blockchain.

The guidelines emphasize that these classifications are not mutually exclusive. In this regard, hybrid tokens are outlined to perform the functions of both asset tokens and payment tokens.

Since there are no fundamental differences between tokens and cryptocurrencies due to their technological similarity and universal economic essence, the general concept of crypto assets can be applied.

For example, the Financial Conduct Authority (FCA) of the United Kingdom in January 2019 issued 
Guidance on Cryptoassets, CP 19/3 [6]. It applied a different classification of crypto assets:

- Exchange tokens are a decentralized tool for buying and selling goods and services without traditional intermediaries;

- Security tokens correspond to the definition of an investment like a stock or debt instrument;

- Utility tokens provide owners with access to the current or presumed good or service.

As we can see, despite specific differences in terminology, the functions performed by crypto assets, in this case, were divided into three main groups. Therefore, there are currently three main functions that cryptoassets perform:

- Means of payment;

- Financial instrument;

- Access to digital platform products and services.

Thus, although financial regulators of different countries have been consistently supporting the globalization of control over the crypto market for a long time, many are skeptical of the developing asset sphere. They do not consider new financial instruments seriously, they postpone the adoption of provisions with direct regulation of new relations, limiting only to point ones.

\section{THE PROSPECTS FOR CRYPTO AS- SETS LEGALIZATION IN RUSSIA}

For the technological leadership of Russia in the field of blockchain, legal regulation of crypto assets is of great importance. However, the prospects for the legalization of cryptocurrency in Russia nowadays are incredibly uncertain. The Bank of Russia has an adamant opinion on this issue. It has repeatedly made comments about the risks of using cryptocurrencies (Information of the Bank of Russia from 27.01.2014 "on the use of "virtual currencies" in transactions, in particular, Bitcoin" [7]; information of the Bank of Russia from 04.09.2017 "on the use of private virtual currencies (cryptocurrencies)" [8].

An attempt to legislate cryptocurrencies was made during the adoption of bill No. 424632-7 "on amendments to parts one, two, and article 1124 of part three of the Civil code of the Russian Federation (on digital rights)" [9].

The bill provided for the consolidation of "digital right" as a basic concept, which meant a token. The category of "digital money" was singled out as a kind of digital right.

It was proposed to recognize under digital money "a set of electronic data (a digital code or symbol) that does not certify the right to any object of civil rights, created in an information system that meets the characteristics of a decentralized information system estab- lished by law, and used for payments by this system users". Based on the proposed definition, it can be concluded that the authors of the bill tried to stipulate instead service (or utility) tokens that are used within the digital platform, but not the cryptocurrency itself.

However, the Bank of Russia did not compromise on the issue, so the digital rights were just mentioned in the Federal law from 18.03.2019 No 34-FZ "On amendments to parts one, two and article 1124 of part three of the Civil code of the Russian Federation" [9].

Thus, in Russian legislation, new objects of property circulation that have a digital nature are related to the category of "digital rights".

It should be noted that the term "digital rights" used in Russian legislation is copied from the American term "digital rights", but their meanings are different. In English-language legal literature, "digital rights" are understood as a set of human rights to use a computer, access to the Internet, publish content in a digital environment. It is processing, transferring, and other rights belong to Internet users (See, for example, Marcus [10]; Goggin et al. [11]). Besides, the expression "digital rights" is used in the term "Digital rights management", which is used concerning any system that controls access to copyrighted material using technological means.

This approach of the Russian legislator to the application of new terminology does not facilitate the harmonization of Russian legislation in the field of the digital economy, which, of course, may have a negative impact on the investment attractiveness of the Russian digital assets market.

Digital rights were included in the list of objects of civil rights, prescribed in paragraph 1 of article 128 of the Civil code, as a type of property rights [12].

The concept of digital rights is described in article 141.1 of the Civil code of the Russian Federation [13], and it says that "digital rights mean obligations and other rights named as such in the law, which content and conditions are determined following the rules of the information system that meets the criteria established by law".

The attempt of the legislator to regulate new objects of property circulation formed with the use of digital technologies has caused a mixed response in the legal community.

First of all, the legal definition of "digital rights" was criticized, where the new digital objects were qualified as "obligations and other rights".

Professor Vasilevskaya believes that "from the point of view of elementary logic, it is impossible to consider digital rights at the same level as the property rights known to us and different in their legal nature (obligation, corporate, etc.)" [14].

Professor Efimova [15], on the contrary, supported the concept proposed by the legislator, offering to consider cryptocurrencies as the objects of absolute digital rights: "The provision 1 of the article 141.1 of the Civil 
code means that these are obligations and "other rights", that means, any other rights. Thus, the wording of provision 1 of article 141.1 of the Civil code allows all previously specified rights, including the absolute right, which object is the cryptocurrency, to be determined as digital rights".

As for Semenov's opinion, the wording "obligations and other rights" is ambiguous and provides different interpretations. As a result, it is possible to:

- "Either to assume that the word "obligation" is mentioned accidentally, since "other" rights include all possible property rights, including absolute ones, as well as obligations from torts and conditionals, etc.;

- Or to conclude that "obligation and other similar rights" are meant, i.e., it is about the only relative, but not about absolute rights;

- Or in an even stricter interpretation, proceed from the fact that we can only mean the rights from deals, and not from torts and conditionals" [16].

It should be agreed that the legislator does not provide an exact answer to the question of what kind of rights can be digital. In this regard, the question arises about what digital rights are different from other subjective civil rights. Thus, Kamyshansky [17] emphasizes that "in fact, digital rights are not a special kind of individual civil rights, different from real or obligation rights. They are obligation and other rights; their content and conditions are contained in a special information system (for example, in the blockchain)". Juggalov also notes that it is the way of account that makes the rights digital, as provided in article 141.1 of the Civil Code [16].

The opinion that digital rights are only a particular way of certifying property rights is quite common in the legal literature. Thus, Vasilevskaya [14] proposes to understand digital rights as a "digital method of fixing property rights", including cession and alienation of these rights. Asoskov also holds a similar opinion: "in reality, digital rights (or tokens, as they are commonly called abroad) are only a special way of certifying (fixing) property rights" [16].

However, it is unlikely that the way of fixing a right or the way of certifying a right can transform the very nature of this right. Subjective law is a theoretical structure, an abstract category, so the form and method of certification of this right do not influence its nature [18].

This is not denied by the followers of this approach, believing that the consolidation of digital rights in the Civil code of the Russian Federation was "a response to the underdevelopment of domestic legislation on nondocumentary securities" [16]. This reasoning does not stand up to criticism, since active measures are being taken to form new legislation on digital assets, despite the existence of effective legislation on securities in the leading foreign countries. In some cases, indeed, there have been attempts in the US to extend the securities regime to certain types of tokens (security/asset tokens), but this is not a reason to identify the entire variety of tokens with one of their types.

Nevertheless, the memorandum to the bill No. 424632-7 explicitly stipulates that "the nature of "digital law" as a new legal fiction is close to the nature of security". The desire to identify digital assets with already known legal categories, such as tokens and securities, is reasonable and can be regarded as an intermediate stage in the enactment of new legislation. However, this approach is challenging to recognize as optimal due to the many legal and economic risks. It is unlikely that the adaptation of the current legislation on securities to the circulation of various types of digital assets is possible and acceptable.

Proponents of this approach deny that digital objects possess any specific economic and legal essence. Sarbash states this most categorically, as for him, "digital rights are the Chimera" [16]. Every year in the world number of so-called crypto pessimists (who consider "bitcoin as a bubble", etc.) is reduced in contrast to the expansion of the use of crypto assets, so their views on the regulation of the stock market can hardly be considered as rational and relevant.

The evident drawback of the legal definition of digital rights is that it does not provide any precise conclusion about what digital objects are meant by digital rights. So, Efimova [15] believes that the concept of digital rights can also cover cryptocurrencies. Others, such as Gongalo and Novoselova [19], believe that the category of digital rights prescribed in article 141.1 of the Civil code of the Russian Federation "does not cover all the above types of tokens that are a marker of property rights. It's much narrower". But from a literal interpretation of the law, it is not even possible to conclude that the digital right means a token. Let alone to guess what kinds of tokens are meant, although experts tend to conclude that they were referring to security tokens.

The question also arises related to mentioned in the law the fact that the content and the implementation of digital rights following the rules of the information system. But what is meant by information systems? The legal definition of an information system is consolidated in article 2 of the Federal law from 27.07.2006 No. 149-FZ (ed. from 01.05.2019) "On information, information technologies and information protection" [20]: "the set of information contained in databases also information technologies and technical means that ensure its processing". 
As it is rightly noted in the legal literature, "the main task of an information system is to meet specific information requirements within a specific subject area based on relevant databases, which is why the term "information system" in practice merges in meaning with the term "database system" [21].

But it follows from the memorandum of the law that it is not about any information systems, but those that meet the "legally established criteria of a decentralized information system ("distributed ledger")". According to the authors, the law, which would have established the criteria of a decentralized system, could be the above-mentioned Federal law, "On information, information technologies, and information protection". Still, it was not amended along with the amendments to the Civil code of the Russian Federation. At the same time, the wording of the bill in part of article 141.1 has been subjected to significant changes.

To implement the principle of legislation's technical neutrality, the reference to "decentralized information system" has been excluded from the wording of the article, which stated that "in the information system that meets the criteria of a decentralized information system established by law". As Novoselova [16] emphasizes, "the considered provision does not contain any technological descriptions of such a system, does not mention either its distributed nature or its reference to certain crypto technologies". This has led to the nonsense that the content and conditions for the implementation of digital rights are determined by the rules of any information system, not just a decentralized one.

However, this is not the worst consequence of such "cutting". Based on the literal interpretation of the law, namely the phrase "information system that meets the criteria established by law", the experts concluded that the legislator had established the principle of legality concerning digital rights. However, there is no one approach in the implementation of this principle concerning digital rights. According to Novoselova, "the law should explicitly stipulate that they can be created and applied as digital rights. The Civil code of the Russian Federation uses a similar structure concerning securities" [19]. This position is shared by Asoskov, pointing out that only those digital rights that are listed in the Federal law will be allowed to be issued and circulated. Uspensky believes that "only those digital rights that are issued through blockchains licensed by Central operators of the Bank of Russia will be considered as legitimate" [19].

It seems that there are no sufficient grounds for any discussions about establishing the principle of legality concerning digital rights. Most likely, the legislator made a technical mistake when editing the text of the bill, which has already happened several times during the "modernization" of the Civil Code.

At the same time, it is necessary to recognize that this error, at least, generates legal uncertainty every time the technology of distributed ledger is used since the application of this technology is impossible without the issue of tokens. For example, when shareholders vote on a digital platform using the blockchain, tokens are issued by the number of shares. Such digital platforms are used in Russia by registrars. Does this mean that the issue of such tokens should be regulated by law, or the blockchain platform should be licensed by the Bank of Russia?

The answer to this question, however, as well as to others, can not be given based on the law interpretation. And these questions are not secondary or irrelevant. Therefore, we should agree with the doubts in the existence of innovations' potential for their practical implementation. The provisions of the Digital rights act did not eliminate the legal uncertainty regarding crypto assets, but, on the contrary, added new risks and uncertainties.

The expectations that the adoption of subsequent laws would explain the provisions of the Civil Code of the Russian Federation on digital rights were not fulfilled. One of these laws is the Federal law of 02.08.2019 N 259-FZ “On investment attracting applying investment platforms and on amendments to certain legislative acts of the Russian Federation" [22] intended to regulate crowdfunding, that is, the relationship on raising funds on select Internet platforms (digital platforms).

Article 8 of the law mentioned above deals with "digital utility rights", although their legal definition has not been stipulated. The concept of utility rights is revealed by listing digital rights that can be acquired, alienated, and implemented in the investment platform. These include:

1. The right to demand the transfer of a thing (things);

2. The right to demand the transfer of exclusive rights to intellectual property and (or) the rights of use of intellectual property;

3. The right to require works performance and (or) services provision.

Based on the content of digital utility law, we can assume that security tokens rather than service (utility) tokens are presumed. Thus, the legislator has made even more confusion in the definitions within the legislation being enacted.

Assuming the overall innovations of Russian legislation in the field of crypto assets, we can conclude that 
they did not make the Russian jurisdiction more friendly and open to the introduction of new digital technologies and investments in this area. It seems that such a disappointing result of a rather lasting joint work of the representatives of legal science and legal practitioners happened because of incorrect approaches to the regulation of the new digital environment.

First, it seems impractical to refuse to apply the terminology that is used worldwide. It must be admitted that this terminology is not well recognized, so there is a risk that the term used by the legislator may become irrelevant over time. So, Japan was the first in the world to regulate cryptocurrencies with the law, by stipulating the definition of "virtual currency" in 2017. But in 2019 , it was decided to use the term "crypto-assets" instead of "virtual currencies" and proceed with respective amendments to the legislation.

Despite this, the approach of the Japanese legislator, who seeks to harmonize national legislation with the world practice of crypto assets circulation, is considered as more promising than the attempts of the Russian legislator to invent something new. The analysis of legislative innovations demonstrates all the difficulties of the Russian legislator's attempts to become a "setter" in the field of crypto assets by introducing such concepts as "digital rights", "digital financial assets", "digital utility rights". The content of these concepts is formulated so indistinctly that there is a necessity to keep in mind more information on the concepts than is prescribed by the law. The literal interpretation does not allow us to understand that it is about crypto-assets created using distributed ledger technology.

This leads to the second mistake of the Russian legislator, such as an extreme dedication to the principle of technological neutrality of the legislation. Proponents of this principle point out rightly that the emergence of new technologies does not always require amendments in legislation, especially significant ones. As an example, the discussions of civilists at the beginning of the century about the recognition of a will written not by hand, but on a typewriter, or about the possibility of concluding a contract by phone, etc. can be mentioned. But at the same time, for some reason, it is overlooked that many legislation fields have appeared due to new technologies, for example, transport legislation. Hardly the rules applied in the nineteenth century for horsedrawn transport can be applied to the relationship with the use of road transport, the same as the rules on road transport can be hardly applied to air transport.

In our opinion, when it comes to changing the form of existing phenomena, such as the use of a printed form instead of a handwritten form, and then electronic, changes in legislation are minimal and, in fact, only legalize the existing status quo. In cases where new technology leads to the emergence of a new object of property circulation, it may be necessary to create a fundamentally new model of legal regulation, which we may observe in the field of crypto assets.

Third, the approach of the Russian legislator to the creation of legislation in the field of crypto-assets should be considered incorrect. Instead of drafting provisions that regulate the relations developing in the crypto market, which development is attractive to the state and society, the legislator tries only to describe new digital phenomena, and in hardly understandable language. As a result, mostly "dead" norms were created, which practical significance, to put it mildly, is not apparent.

It seems that the legislator did not seek to create an effective legal regime of new digital objects for their involvement in property circulation. To a certain extent, this is confirmed by the memorandum to the bill No. 424632-7, where the developers warn that "the task of the bill is not to describe the conditions of possibility of so-called digital objects circulation." However, the authors of the bill did not explain what the purpose was. The consolidation of new digital objects as a type of property rights was not required due to the presumption of civil rights circulation enshrined in article 129 of the Civil Code of the Russian Federation [23].

It is possible that this approach was prompted by the lack of consensus in the political field on the issue of the legalization of digital assets in the financial sphere, mainly cryptocurrencies. The Bank of Russia continues to have an extremely aggressive opinion on this issue, preferring to ignore the new phenomena in the field of finance and technology, recognized and developed around the world. Thanks to the efforts of the Bank of Russia, the best definition for cryptocurrency in Russia is "Something-That-Must-Not-Be-Named" (See Rolling [24]).

The uselessness of such a descriptive approach was evident from the very beginning. It is impossible to outline the concept of a phenomenon without an indepth scientific study of its legal nature. That is why foreign legislators and regulators, who acted as first ones in the regulation of the crypto market, did not seek to fix the comprehensive concepts of new digital objects but defined them by pointing to the functions they perform in the digital environment.

It seems that for the formation of the concept of crypto-assets and their legal regime as new objects of civil rights, it is necessary to identify their significant legal features based on the study of their technological features and their role in the economy. At this stage, the world is in the process of accumulating enough knowledge that will allow us to develop an optimal legal regulation. 
But this quite natural process should not impede the development and implementation of new digital technologies, as well as the property circulation of crypto assets. Russia has a substantial human potential in the field of IT-technologies, which could be used for a breakthrough in the field of financial technology. However, the new Russian legislation does not leave crypto (blockchain) enthusiasts any chance, making them apply more loyal jurisdictions. Many Russian companies implement their blockchain projects in Switzerland. Thus, the National Settlement Depository (NSD) plans to launch a blockchain platform for security tokens in Switzerland.

\section{CONCLUSIONS}

As proved by the research, the state's technological leadership, the digital economy's formation and the transition to a new technological order is possible only with the active introduction of new digital technologies in business processes. The law's role is to establish an enabling, friendly environment for the distribution of digital technologies. This is discussed both in Russia and abroad.

The task of creating a new type of economy in Russia - the digital economy requires a balanced approach to the legal regulation of relations arising from the use of blockchain technology. The formation of new legal rules should not base on the rules applied and tested on the legal regime of things and objects of the real world.

Nowadays, the expectations of the market and the business community are focused primarily on the achievement of legal certainty and the possibility of protection of violated rights and legitimate interests in court. In our opinion, it is necessary to create a regulatory environment that is appropriate to the essence of the digital economy.

\section{ACKNOWLEDGMENTS}

The Russian Foundation for Basic Research supported this research via grant No: 18-29-16145 MK "The Mechanism of legal regulation of relations using the Distributed Ledger Technology."

\section{REFERENCES}

[1] R. Windsor (2017) Defining Digital Assets. Digital Asset News.https://digitalassetnews.org/assets/definingdigital-assets/ Accessed 26 Jun 2020

[2] L-D. Ibáñez, M.R. Hoffman, T. Choudhry (2018) Blockchains and Digital Assets. https://www.eublockchainforum.eu/sites/default/files/re search- pa-

per/blockchains_and_digital_assets_june_version.pdf? width $=1024 \&$ height $=800 \&$ iframe $=$ true Accessed 26 Jun 2020

[3] V.A. Laptev, Digital assets as objects of civil rights, Legal science and practice, Bulletin of the Nizhny Novgorod Academy of the Ministry of internal Affairs of Russia 2(42) (2018) 138-158.

[4] K. Ruan, Digital Asset Valuation and Cyber Risk Measurement: Principles of Cybernomics, Academic Press, 2018, pp. 7-8.

[5] FINMA (2018) Guidelines for inquiries regarding the regulatory framework for initial coin offers (ICOs). https://www.iosco.org/library/ico-

statements/Switzerland\%20-\%20FINMA\%20-

\%20ICO\%20Guidelines.pdf Accessed 26 Jun 2020

[6] PS19/22: Guidance on Cryptoassets (CP 19/3) by Financial Conduct Authority (FCA) of the United Kingdom https://www.fca.org.uk/publication/consultation/cp1903.pdf Accessed 26 Jun 2020

[7] Information of the Bank of Russia from "on the use of "virtual currencies" in transactions, in particular, Bitcoin

https://cbr.ru/press/PR/?file=27012014_1825052.htm

Accessed 29 Sep 2020

[8] Information of the Bank of Russia from "on the use of private" virtual currencies "(cryptocurrencies)" (2017)

https://cbr.ru/press/PR/?file=27012014_1825052.htm Accessed 29 Sep 2020

[9] A bill No. 424632-7 "On amendments to parts one, two, and article 1124 of part three of the Civil code of the Russian Federation (on digital rights)" https://sozd.duma.gov.ru/bill/424632-7 Accessed 29 Sep 2020

[10] G. Marcus (2015) Human rights and the new (ish) digital paradigm. https://sasspace.sas.ac.uk/6205/1/06marcus.pdf Accessed 26 Jun 2020

[11] G. Goggin et al., Digital rights in Australia, The University of Sydney Law School, 2017, 71 p.

[12] Paragraph 1 of article 128 of the Civil code, as a type of property rights Civil code of the Russian Federation http://www.consultant.ru/document/cons_doc_LAW_5 142/ Accessed 29 Sep 2020

[13] Article 141.1 of the Civil code of the Russian Federation Civil code of the Russian Federation. 
http://www.consultant.ru/document/cons_doc_LAW_5 142/ Accessed 29 Sep 2020

[14] L.V. Vasilevskaya, Digital rights as a new object of civil rights: problems of legal qualification, Business and Law Journal 5 (2019) 3-14.

[15] L.G. Efimova, Cryptocurrency as an object of civil law, Economy and law 4 (2019) 17-25.

[16] L. Novoselova et al., Digital rights as a new object of civil law, Law 5 (2019) 31-54.

[17] V.P. Kamyshansky, On digital technology and digital law, Power of Law 1 (2019) 14-18.

[18] L.V. Sannikova, A.I. Paderov, Legalization of cryptocurrency in Russia: problems and prospects, Property relations in the Russian Federation 9 (2008) 21-27.

[19] B.M. Gongalo, L.A Novoselova, Is there a place for "digital rights" in the system of civil law objects, Perm Legal Almanac 2 (2019) 179-192.

[20] Federal law from 27.07.2006 No. 149-FZ (ed. from 01.05.2019) "On information, information technologies and information protection". http://www.consultant.ru/document/cons_doc_LAW_6 1798/ Accessed 29 Sep 2020

[21] R.B. Golovkin, O.S. Amosova, "Digital rights" and "digital law" in the mechanisms of digitalization of the economy and public administration, Vestnik Vladim. the faculty of law 2(51) (2019) 163-166.

[22] Federal law of 02.08.2019 N 259-FZ “On investment attracting applying investment platforms and on amendments to certain legislative acts of the Russian Federation".

http://www.consultant.ru/document/cons_doc_LAW_3 30652/ Accessed 29 Sep 2020

[23] Civil code of the Russian Federation. http://www.consultant.ru/document/cons_doc_LAW_5 142/ Accessed 29 Sep 2020

[24] J.K. Rolling, Harry Potter and the philosopher's stone, Rosmen Press, 2001, 398 p. 